\title{
The mitochondrial genomes of Ancylostoma caninum and Bunostomum phlebotomum - two hookworms of animal health and zoonotic importance
}

\author{
Aaron R Jex ${ }^{1}$, Andrea Waeschenbach*2, Min $\mathrm{Hu}^{1}$, Jan A van Wyk ${ }^{3}$, \\ Ian Beveridge ${ }^{1}$, D Timothy J Littlewood ${ }^{2}$ and Robin B Gasser ${ }^{1}$
}

Address: ${ }^{1}$ Department of Veterinary Science, The University of Melbourne, 250 Princes Highway, Werribee, Victoria 3030, Australia, ${ }^{2}$ Department of Zoology, The Natural History Museum, Cromwell Road, London, UK and ${ }^{3}$ Department of Veterinary Tropical Diseases, Faculty of Veterinary Science, University of Pretoria, Private Bag X04, 0110 Onderstepoort, South Africa

Email: Aaron R Jex - ajex@unimelb.edu.au; Andrea Waeschenbach* - a.waeschenbach@nhm.ac.uk; Min Hu - mhu@unimelb.edu.au; Jan A van Wyk - janvwyk@op.up.ac.za; Ian Beveridge - ibeve@unimelb.edu.au; D Timothy J Littlewood - t.littlewood@nhm.ac.uk;

Robin B Gasser - robinbg@unimelb.edu.au

* Corresponding author

Published: II February 2009

BMC Genomics 2009, 10:79 doi:10.1186/147I-2164-10-79
Received: 18 September 2008

Accepted: II February 2009

This article is available from: http://www.biomedcentral.com/I47/-2/64/10/79

(C) 2009 Jex et al; licensee BioMed Central Ltd.

This is an Open Access article distributed under the terms of the Creative Commons Attribution License (http://creativecommons.org/licenses/by/2.0), which permits unrestricted use, distribution, and reproduction in any medium, provided the original work is properly cited.

\begin{abstract}
Background: Hookworms are blood-feeding nematodes that parasitize the small intestines of many mammals, including humans and cattle. These nematodes are of major socioeconomic importance and cause disease, mainly as a consequence of anaemia (particularly in children or young animals), resulting in impaired development and sometimes deaths. Studying genetic variability within and among hookworm populations is central to addressing epidemiological and ecological questions, thus assisting in the control of hookworm disease. Mitochondrial $(\mathrm{mt})$ genes are known to provide useful population markers for hookworms, but $\mathrm{mt}$ genome sequence data are scant.

Results: The present study characterizes the complete mt genomes of two species of hookworm, Ancylostoma caninum (from dogs) and Bunostomum phlebotomum (from cattle), each sequenced (by 454 technology or primer-walking), following long-PCR amplification from genomic DNA ( 20-40 ng) isolated from individual adult worms. These $\mathrm{mt}$ genomes were $13717 \mathrm{bp}$ and $13790 \mathrm{bp}$ in size, respectively, and each contained 12 protein coding, 22 transfer RNA and 2 ribosomal RNA genes, typical for other secernentean nematodes. In addition, phylogenetic analysis (by Bayesian inference and maximum likelihood) of concatenated $\mathrm{mt}$ protein sequence data sets for 12 nematodes (including Ancylostoma caninum and Bunostomum phlebotomum), representing the Ascaridida, Spirurida and Strongylida, was conducted. The analysis yielded maximum statistical support for the formation of monophyletic clades for each recognized nematode order assessed, except for the Rhabditida.

Conclusion: The mt genomes characterized herein represent a rich source of population genetic markers for epidemiological and ecological studies. The strong statistical support for the construction of phylogenetic clades and consistency between the two different tree-building methods employed indicate the value of using whole $\mathrm{mt}$ genome data sets for systematic studies of nematodes. The grouping of the Spirurida and Ascaridida to the exclusion of the Strongylida was not supported in the present analysis, a finding which conflicts with the current evolutionary hypothesis for the Nematoda based on nuclear ribosomal gene data.
\end{abstract}




\section{Background}

Hookworms (Nematoda: Strongylida: Ancylostomatoidea) are blood-feeding nematodes that inhabit the small intestines of their mammalian host. Species of Ancylostoma, Necator, Bunostomum and Globocephalus, for instance, are of major human or animal health significance in various countries [1-6]. The infective, third-stage larvae (L3) can be ingested or penetrate the skin of the host and migrate via the circulatory system and the lungs to finally reside, as dioecious adults, usually in the duodenum. The adults attach via their buccal capsule to the intestinal mucosa, rupture capillaries and feed on blood. The pathogenesis of hookworm disease in humans and other animals is mainly a consequence of the blood loss, which occurs during parasite attachment and feeding in the intestine. Cutaneous infection can occur and is often associated with inflammatory/immune responses and painful, eruptive lesions during the migration of larvae through the skin $[7,8]$.

Current estimates indicate that more than 740 million people are infected with the hookworms Ancylostoma duodenale and Necator americanus [9], and $\sim 80$ million are severely clinically affected by hookworm disease [10]. In a large number of developing countries, hookworms are a leading cause of iron deficiency anaemia, which, in heavy infections, can cause physical and mental retardation and deaths in children as well as adverse maternal-foetal outcomes $[10,11]$. Although there is considerably less information on the prevalence and geographical distribution of hookworms of animals [7,12-15], these parasites are also clinically important in dogs (Ancylostoma braziliense, Ancylostoma caninum, Ancylostoma ceylanicum and Uncinaria stenocephala), cats (Ancylostoma tubaeforme), ruminants (Bunostomum phlebotomum, Bunostomum trigonocephalum and Gaigeria pachyscelis), pigs (e.g., Globocephalus urosubulatus) and other hosts [16]. Hookworms were originally thought to be host-specific $[17,18]$; however, the canine hookworm, Ancylostoma caninum, for example, can infect humans and cause dermatitis and eosinophilic enteritis [19], and some hookworm species, such as the bovine hookworm, Bunostomum phlebotomum, have been linked to cutaneous lesions in humans [20]. Significant genetic variation has been described among individuals of Ancylostoma caninum from dogs in Australia [21]. Such variation might reflect differences in host specificity, infectivity and/or pathogenicity among individual nematodes within a population or, in some cases, might be indicative of speciation events, as has been hypothesized previously for human hookworms [21,22]. Presently, there are no published studies of genetic variation within and among populations of Bunostomum phlebotomum and no molecular data are publicly available for this species.
The ability to accurately identify hookworms to species and to assess genetic variability in hookworm populations is central to studying their epidemiology as well as to diagnosis and control. Sequences of the first and second internal transcribed spacers (ITS-1 and ITS-2) of nuclear ribosomal DNA (rDNA) [23-25] and of cAMP-dependent protein kinase [26] have been utilized to identify and differentiate hookworm species. However, the ITS- 1 and ITS2 regions do not usually display sufficient within-species sequence variability to enable the study of the genetic structuring within and among hookworm populations [24]. In contrast, mitochondrial ( $\mathrm{mt}$ ) genomes have been shown to contain useful genetic markers for studying the population structures of hookworm species [27-31], because of their rapid mutation rates and apparent maternal inheritance [32-34]. Although the protein-coding $\mathrm{mt}$ gene cytochrome $c$ oxidase subunit 1 (cox 1$)$ is applicable to population studies of a range of invertebrates, including parasitic platyhelminths $[35,36]$ and some nematodes $[37,38]$, there are still limited sequence data for cox 1 and other $\mathrm{mt}$ genes of hookworms, and limited published information is available on sequence heterogeneity therein. Building on advances in long polymerase chain reaction (PCR)-based mt genome sequencing [39-41], the present study determined the sequences and structures of the two mt genomes from an individual of Ancylostoma caninum (from a dog) from Australia and a specimen of Bunostomum phlebotomum (from a calf) from South Africa. The sequences derived for the $\mathrm{mt}$ genomes of these two hookworms were compared in detail with $\mathrm{mt}$ genomic data available for the predominant hookworms of humans, Ancylostoma duodenale and Necator americanus [42], as well as those available for other selected species belonging to the orders Strongylida [41], Ascaridida [4345] and Spirurida [46-48].

\section{Results and Discussion \\ Mitochondrial genome features, characteristics and gene organization}

The circular $\mathrm{mt}$ genomes of Ancylostoma caninum and Bunostomum phlebotomum, sequenced from single adult worms, were 13717 and 13790 bp in size, respectively (Figure 1). Each genome contained 36 genes, including 12 protein coding genes (adenosine triphosphatase subunit 6 [atp6], the cytochrome $c$ oxidase subunits [cox1-3], cytochrome $b[c y t b]$, and the nicotinamide dehydrogenase subunits [nad1-6 and nad4l]), 22 transfer RNA (tRNA) genes and 2 ribosomal RNA genes (small [rrnS] and large $[r r n \mathrm{~L}]$ subunits), and was consistent with gene arrangement 2 (GA2) [49]. This arrangement is characteristic for the mt genomes of all members of the Strongylida and Ascaridida, as well as the free-living nematode Caenorhabditis elegans (Rhabditida), but not for Strongyloides stercoralis (Rhabditida) [41-49]. In accordance with other species of Strongylida for which complete mt genome 


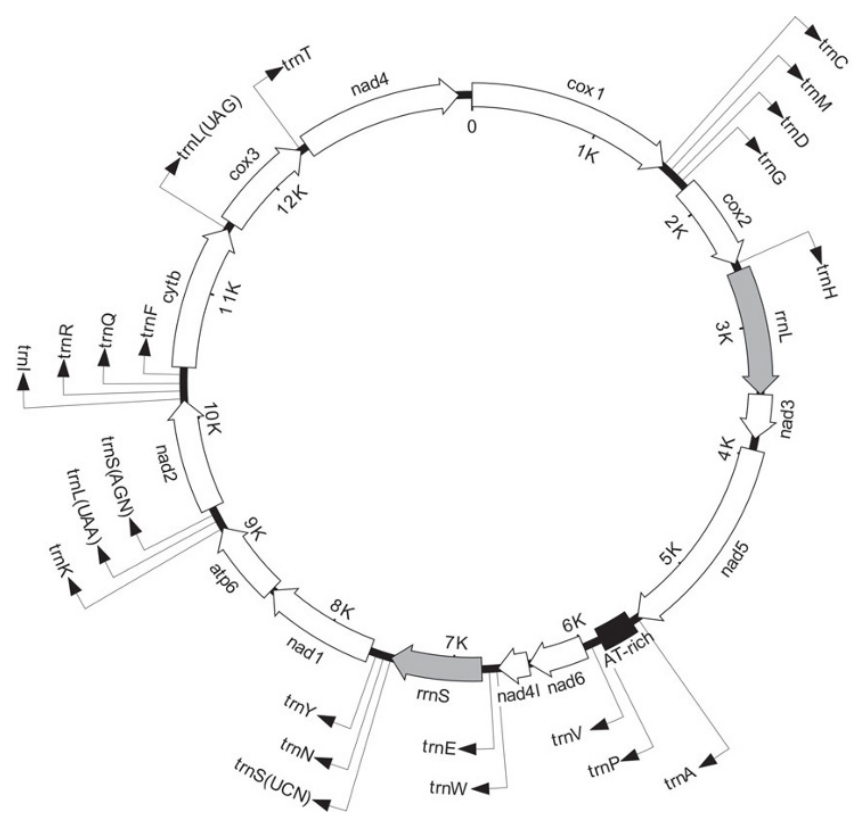

Figure I

A representation of the circular mt genomes of Ancylostoma caninum ( 137 I 7 bp) and Bunostomum phlebotomum ( $13790 \mathrm{bp}$ ) (GenBank accession numbers FJ4835 I 8and FJ4835 I7, respectively). All I 2 protein-coding genes and the large and small ribosomal RNA genes are indicated. Each tRNA gene is identified by its single letter amino acid code, according to the international union of pure and applied chemistry (IUPAC) code. The two leucine and the two serine tRNA genes are differentiated by their respective anti-codons (in brackets). The direction of transcription is indicated by an arrow. The circular map has been drawn approximately to scale; "K" indicates sequence length in 'thousands of base pairs' from the first nucleotide position of the cytochrome $c$ oxidase subunit I (coxl) gene.

sequences are available $[41,42]$, the AT-rich regions for both Ancylostoma caninum and Bunostomum phlebotomum were located between the genes nad5 and nad6, flanked at the 5 '-end by the tRNA gene for alanine, and at the 3'-end by the tRNA genes for proline and alanine.

Each protein-coding gene for each of the two species had an open reading frame (ORF), and all genes were located on the same strand and transcribed in the same direction (5' to 3'), consistent with the known mt genomes of secernentean nematodes [37]. The nucleotide usages (coding strand) of A, C, G and T in each mt genome were $29.0 \%$, 6.5\%, 16.1\% and 48.5\%, respectively, for Ancylostoma caninum (Table 1) and 26.9\%, 6.2\%, 16.7\% and 50.1\%, respectively, for Bunostomum phlebotomum (Table 1), with overall A+T contents of $77.5 \%$ and $77.0 \%$, respectively. The A+T content of protein coding genes ranged from 70.9\% (cox1) to $81.3 \%$ (nad6) for Ancylostoma caninum, and from $70.4 \%$ (cox 1$)$ to $82.6 \%$ (nad3) for Bunostomum phlebotomum. The A+T content for $r r n S, r r n \mathrm{~L}$ (= ribosomal RNA genes) and the AT-rich region were 78.1\%, 80.9\% and 90.1\%, respectively, for Ancylostoma caninum, and $75.2 \%, 82.4 \%$ and $88.0 \%$, respectively, for Bunostomum phlebotomum. For the mt genome of Ancylostoma caninum, codon usage in individual protein coding genes $(n=12)$ ranged from $0 \%$ for CGC (arginine) and CCC (proline) to $15.7 \%$ for TTT (phenylalanine). For the mt genome of Bunostomum phlebotomum, codon usage ranged from $0 \%$ for CGC (arginine), CAC (histidine), CTC (leucine), CCC (proline), TCC (serine) and GTC (valine) to $15.0 \%$ for TTT (phenylalanine). For both species, individual tRNA structures were consistent with those predicted previously for hookworms and other secernentean nematodes $[37,42,45,50,51]$. All tRNA genes, except trnS(AGN) and trnS(UCN), had a predicted secondary structure containing a TV-replacement loop instead of the T $\psi \mathrm{C}$ arm and loop (not shown). The predicted secondary structure of each of the two serine tRNAs contained the T $\psi \mathrm{C}$ arm and loop but lacked the DHU loop. The genes $r r n S$ and $r r n \mathrm{~L}$ were $694 \mathrm{bp}$ and $935 \mathrm{bp}$ in length, respectively; the predicted secondary structures for the ribosomal RNA gene subunits for Ancylostoma caninum and Bunostomum phlebotomum (not shown) were similar to those of Necator americanus and Ancylostoma duodenale [42], which is also supported by the high nucleotide sequence similarity in the mt genes among these four hookworms (see Tables 2 and 3).

The AT-rich regions for Ancylostoma caninum and Bunostomum phlebotomum were 272 bp and 234 bp, respectively, and both exhibited complex secondary structures (not shown), as predicted previously for the AT-rich regions of nematodes $[41,42,45,47,49]$. Four AT-repeat regions of variable length were identified in the AT-rich region of the mt genome of Ancylostoma caninum: two were 6 nucleotides (nt) (3 AT-repeats), one was $14 \mathrm{nt}$ (7 AT-repeats) and the longest was $16 \mathrm{nt}$ (8 AT-repeats). Similar dinucleotide repeats have been described in the ATrich region of the $\mathrm{mt}$ genomes of other nematode species (e.g., $[41,42,44])$. Other repetitive elements have been identified within this region in the free-living nematode Caenorhabditis elegans, the largest and most conspicuous of which are the repetitive sequence motifs CR1-CR6 [45]. However, no such elements were identified in the AT-rich region of the mt genome of either Ancylostoma caninum, Bunostomum phlebotomum or any other species of animal-parasitic nematode sequenced to date $[41,44,47,49]$.

\section{Comparative analyses with other nematodes}

The identities (\%) in inferred amino acid sequences of each protein-coding mt gene were calculated based upon pairwise comparisons between Ancylostoma caninum and Bunostomum phlebotomum (Tables 2 and 3). Based on these comparisons, the sequence identities (in decreasing 
Table I: Nucleotide (nt) composition (\%) and A+T contents (\%) of the 12 mitochondrial protein coding genes.

\begin{tabular}{|c|c|c|c|c|c|c|c|c|c|c|c|c|}
\hline \multirow[b]{2}{*}{ Gene or region } & \multicolumn{6}{|c|}{ Ancylostoma caninum } & \multicolumn{6}{|c|}{ Bunostomum phlebotomum } \\
\hline & Length (nt) & $\mathbf{A}$ & $\mathbf{C}$ & $\mathbf{G}$ & $\mathbf{T}$ & $A+T$ & Length (nt) & $\mathbf{A}$ & $\mathbf{C}$ & $\mathbf{G}$ & $\mathbf{T}$ & $\mathbf{A}+\mathbf{T}$ \\
\hline atp6 & 600 & 29.0 & 6.0 & 16.5 & 48.5 & 77.5 & 600 & 25.7 & 5.2 & 18.0 & 51.2 & 76.8 \\
\hline $\operatorname{cox} 1$ & 1578 & 25.3 & 9.6 & 19.5 & 45.6 & 70.9 & 1578 & 25.2 & 9.6 & 19.5 & 45.7 & 70.9 \\
\hline $\cos 2$ & 696 & 29.0 & 7.5 & 18.5 & 45.0 & 73.4 & 696 & 26.0 & 7.5 & 19.0 & 47.6 & 73.6 \\
\hline $\cos 3$ & 766 & 23.0 & 7.6 & 18.7 & 50.8 & 73.8 & 766 & 24.2 & 7.0 & 17.6 & 51.2 & 75.3 \\
\hline cytb & 1113 & 26.3 & 7.6 & 17.6 & 48.4 & 74.8 & 1113 & 24.6 & 7.4 & 17.9 & 50.1 & 74.8 \\
\hline nadl & 870 & 23.9 & 7.5 & 18.4 & 50.2 & 74.1 & 870 & 22.2 & 7.4 & 20.6 & 49.9 & 72.1 \\
\hline $\operatorname{nad} 2$ & 846 & 27.3 & 5.1 & 14.4 & 53.2 & 80.5 & 846 & 24.0 & 4.3 & 15.0 & 56.7 & 80.7 \\
\hline nad3 & 336 & 26.8 & 2.4 & 17.3 & 53.6 & 80.4 & 336 & 27.1 & 2.4 & 14.9 & 55.6 & 82.7 \\
\hline nad4 & 1230 & 27.6 & 7.1 & 13.5 & 51.8 & 79.4 & 1230 & 24.5 & 6.6 & 13.5 & 55.4 & 79.9 \\
\hline nad4L & 234 & 26.9 & 3.0 & 16.2 & 53.9 & 80.8 & 234 & 24.4 & 3.4 & 17.5 & 54.7 & 79.1 \\
\hline nad5 & 1582 & 26.6 & 5.3 & 16.6 & 51.5 & 78.I & 1582 & 26.2 & 4.9 & 16.7 & 52.2 & 78.4 \\
\hline nad6 & 432 & 25.7 & 3.2 & 15.5 & 55.6 & 81.3 & 432 & 20.6 & 4.4 & 17.8 & 57.2 & 77.8 \\
\hline$r r n L$ & 963 & 36.2 & 5.9 & 13.2 & 44.7 & 80.9 & 963 & 34.7 & 5.6 & 12.0 & 47.6 & 82.3 \\
\hline$r r n S$ & 694 & 37.0 & 6.8 & 15.1 & 41.1 & 78.1 & 694 & 34.0 & 7.5 & 17.3 & 41.2 & 75.2 \\
\hline AT-rich & 272 & 44.1 & 6.3 & 2.9 & 46.7 & 90.1 & 234 & 40.6 & 4.7 & 7.3 & 47.4 & 88.0 \\
\hline Genome & 13735 & 28.9 & 6.4 & 16.1 & 48.5 & 77.4 & 13790 & 26.9 & 6.2 & 16.7 & 50.1 & 77.0 \\
\hline
\end{tabular}

Large and small ribosomal RNA subunits, AT-rich regions and complete mitochondrial genomes of Ancylostoma caninum and Bunostomum phlebotomum.

order) were COX1 (97.3\%), COX3 (96.0\%), NAD4L (93.5\%), COX2 (89.6\%), СYTB (87.0\%), ATP6 (85.9\%), NAD1 $(84.4 \%)$, NAD3 (81.9\%), NAD4 $(79.2 \%)$, NAD5 (78.5\%), NAD2 (72.5\%) and NAD6 (67.3\%). In addition, the amino acid sequences inferred from each coding $\mathrm{mt}$ gene of Ancylostoma caninum and Bunostomum phlebotomum were compared, again in a pairwise manner, with those inferred from published $\mathrm{mt}$ genomes of Anisakis simplex [43], Ascaris suum [45] and Toxocara canis [44] (Ascaridida), Ancylostoma duodenale, Necator americanus [42] and Haemonchus contortus [41] (Strongylida), and Brugia malayi [46], Dirofilaria immitis [47] and Onchocerca volvulus [48] (Spirurida). The most conserved protein sequences among all species, assessed relative to Ancylostoma caninum and Bunostomum phlebotomum, were inferred to be COX1, COX3 and NAD4L, and the least conserved were NAD2 and NAD6 (see Tables 2 and 3).

\section{Phylogenetic analyses of selected species of Ascaridida, Spirurida and Strongylida using concatenated amino acid sequence data inferred from $\mathrm{mt}$ genes}

Because of the high degree of intraspecific variation in nucleotide sequence in the $\mathrm{mt}$ genes of nematodes $[37,38,52]$ and the limited availability or lack of multiple

Table 2: Pairwise comparison (\%) of the amino acid sequences inferred for each of the mitochondrial protein coding genes.

\begin{tabular}{|c|c|c|c|c|c|c|c|c|c|c|c|}
\hline Protein or gene & & $B p$ & Ad & $\mathrm{Na}$ & $H c$ & Ans & Ass & Tc & $\mathrm{Bm}$ & $D i$ & Ov \\
\hline ATP6 & & 85.9 & 98.4 & 89.4 & 82.4 & 76.3 & 77.3 & 76.8 & 19.8 & 22.2 & 21.2 \\
\hline COXI & & 97.3 & 99.2 & 97.1 & 94.4 & 89.5 & 90.4 & 91.2 & 50.7 & 50.9 & 51.4 \\
\hline $\operatorname{cox} 2$ & & 89.6 & 96.1 & 92.6 & 88.3 & 83.1 & 83.6 & 84.4 & 41.0 & 42.3 & 41.0 \\
\hline $\mathrm{cox} 3$ & & 96.0 & 99.2 & 95.2 & 91.0 & 81.5 & 81.9 & 84.7 & 33.9 & 33.5 & 32.0 \\
\hline CYTB & & 87.0 & 98.1 & 85.9 & 81.6 & 70.8 & 74.5 & 73.5 & 51.0 & 48.9 & 50.8 \\
\hline NADI & & 84.4 & 95.1 & 87.9 & 75.5 & 70.0 & 71.7 & 70.8 & 46.8 & 50.6 & 49.1 \\
\hline NAD2 & & 72.5 & 90.0 & 77.9 & 51.6 & 48.9 & 46.5 & 51.2 & 33.3 & 28.7 & 32.0 \\
\hline NAD3 & & 81.9 & 96.3 & 81.0 & 69.3 & 67.5 & 68.4 & 66.6 & 35.7 & 35.7 & 35.7 \\
\hline NAD4 & & 79.2 & 95.1 & 85.8 & 73.1 & 64.3 & 63.5 & 63.0 & 45.2 & 44.9 & 45.8 \\
\hline NAD4L & & 93.5 & 100.0 & 93.5 & 69.6 & 75.3 & 72.7 & 68.8 & 35.0 & 29.1 & 37.5 \\
\hline NAD5 & & 78.5 & 94.3 & 83.6 & 71.1 & 66.0 & 63.4 & 65.5 & 38.9 & 37.4 & 39.3 \\
\hline \multirow[t]{3}{*}{ NAD6 } & & 67.3 & 88.8 & 70.8 & 51.3 & 59.0 & 56.2 & 51.3 & 26.4 & 26.4 & 27.1 \\
\hline & $r r n L$ & 83.4 & 91.6 & 82.5 & 75.4 & 70.5 & 70.0 & 66.4 & 62.6 & 61.3 & 60.4 \\
\hline & $r r n S$ & 86.8 & 94.9 & 86.5 & 78.7 & 73.0 & 73.3 & 70.9 & 60.6 & 60.6 & 59.4 \\
\hline
\end{tabular}

In addition: nucleotide sequences for each of the ribosomal RNA genes of Ancylostoma caninum ( $A c$ ) and Bunostomum phlebotum (Bp) with those published for species of Strongylida [Ancylostoma duodenale (Ad), Necator americanus ( $\mathrm{Na}$ ) and Haemonchus contortus (Hc)], species of Ascaridida [Anisakis simplex (Ans), Ascaris suum (Ass) and Toxocara canis (Tc)] and species of Spirurida [Brugia malayi (Bm), Dirofilaria immitis (Di) and Onchocerca volvulus $(O v)]$. 
Table 3: Pairwise comparison (\%) of the amino acid sequences inferred for each of the mitochondrial protein coding genes and nucleotide sequences for each of the ribosomal RNA genes of Ancylostoma caninum (Ac) and Bunostomum phlebotum (Bp).

\begin{tabular}{|c|c|c|c|c|c|c|c|c|c|c|c|}
\hline Protein or gene & & Ac & Ad & $\mathrm{Na}$ & Hc & Ans & Ass & Tc & $\mathrm{Bm}$ & $D i$ & Ov \\
\hline ATP6 & & 85.9 & 85.4 & 86.9 & 78.8 & 73.3 & 74.3 & 74.8 & 19.8 & 21.7 & 21.2 \\
\hline COXI & & 97.3 & 96.9 & 97.3 & 94.2 & 89.7 & 90.8 & 91.6 & 50.7 & 50.9 & 51.4 \\
\hline $\operatorname{cox} 2$ & & 89.6 & 88.3 & 92.2 & 87.4 & 79.7 & 82.7 & 81.8 & 41.4 & 41.8 & 40.5 \\
\hline $\operatorname{cox} 3$ & & 96.0 & 95.6 & 94.5 & 91.8 & 80.7 & 82.3 & 83.5 & 33.2 & 33.2 & 32.0 \\
\hline CYTB & & 87.0 & 87.0 & 83.7 & 79.1 & 69.4 & 73.2 & 72.4 & 53.2 & 51.6 & 53.5 \\
\hline NADI & & 84.4 & 84.4 & 84.8 & 74.4 & 69.3 & 69.6 & 69.5 & 48.4 & 52.3 & 50.1 \\
\hline NAD2 & & 72.5 & 71.1 & 69.7 & 50.1 & 53.5 & 48.1 & 52.2 & 35.4 & 30.8 & 35.2 \\
\hline NAD3 & & 81.9 & 81.9 & 75.6 & 67.5 & 64.8 & 67.5 & 63.9 & 38.3 & 37.5 & 39.2 \\
\hline NAD4 & & 79.2 & 79.4 & 80.6 & 69.6 & 67.4 & 65.0 & 65.0 & 45.2 & 44.4 & 44.1 \\
\hline NAD4L & & 93.5 & 93.5 & 92.2 & 65.8 & 71.4 & 68.8 & 64.9 & 30.3 & 37.5 & 33.7 \\
\hline NAD5 & & 78.5 & 77.9 & 79.1 & 67.3 & 63.2 & 64.7 & 64.5 & 42.1 & 39.1 & 39.9 \\
\hline \multirow[t]{3}{*}{ NAD6 } & & 67.3 & 70.1 & 70.8 & 48.6 & 58.3 & 57.6 & 52.7 & 27.8 & 28.4 & 29.8 \\
\hline & $r r n L$ & 83.4 & 82.6 & 80.2 & 73.9 & 69.2 & 70.1 & 67.5 & 63.9 & 62.8 & 61.6 \\
\hline & $r r n S$ & 86.8 & 85.6 & 86.0 & 75.6 & 74.5 & 71.2 & 70.6 & 61.1 & 61.3 & 60.5 \\
\hline
\end{tabular}

With those published for species of Strongylida [Ancylostoma duodenale (Ad), Necator americanus $(\mathrm{Na})$ and Haemonchus contortus $(\mathrm{Hc})$ ], species of Ascaridida [Anisakis simplex (Ans), Ascaris suum (Ass) and Toxocara canis (Tc)] and species of Spirurida [Brugia malayi (Bm), Dirofilaria immitis (Di) and Onchocerca volvulus $(\mathrm{Ov})]$.

mt genome sequences for each species, previous work has suggested that phylogenetic analyses for nematodes be conducted using concatenated amino acid sequence datasets, utilizing sequences inferred from individual $\mathrm{mt}$ protein coding genes [47]. In order to further assess systematic relationships within and among members of the Ascaridida, Spirurida and Strongylida, a phylogenetic analysis was carried out using Bayesian inference (BI) and maximum likelihood (ML) (Figure 2). Almost all clades in the consensus tree were supported by maximum BI posterior probability $(\mathrm{pp})$ values $(\mathrm{pp}=1.00$; expressed as a percentage in Figure 2) and/or ML bootstrap support (100). The phylogenetic analysis conducted herein clearly supports the distinct classification of the orders Ascaridida, Spirurida and Strongylida, each as monophyletic clades with maximum statistical support. The order Rhabditida appears to be paraphyletic, with Caenorhabditis elegans grouping closely with the Strongylida, and Steinernema carpocapsae and Strongyloides stercoralis placed externally to a clade comprising the Ascaridida, Strongylida and C. elegans. This relationship is consistent with the proposed molecular phylogeny for the Nematoda based on small subunit (18S) nuclear ribosomal DNA data [53]. In addition, the hookworms were represented as a monophyletic clade within the Strongylida.

For hookworms, the phylogenetic analysis using BI indicated a closer relationship between Ancylostoma spp. and Necator americanus than between either of them and Bunostomum phlebotomum. This finding conflicts with the current classification of the Strongylida [16], wherein both Necator and Bunostomum are placed within the subfamily Bunostominae, whereas Ancylostoma is placed within the subfamily Ancylostominae (poorly supported by the ML analysis; bootstrap support = 47). A larger analysis, including $\mathrm{mt}$ data for more hookworm species, is needed to test further this hypothesis.

The present phylogenetic analysis did not support the grouping of the Ascaridida and Spirurida to the exclusion

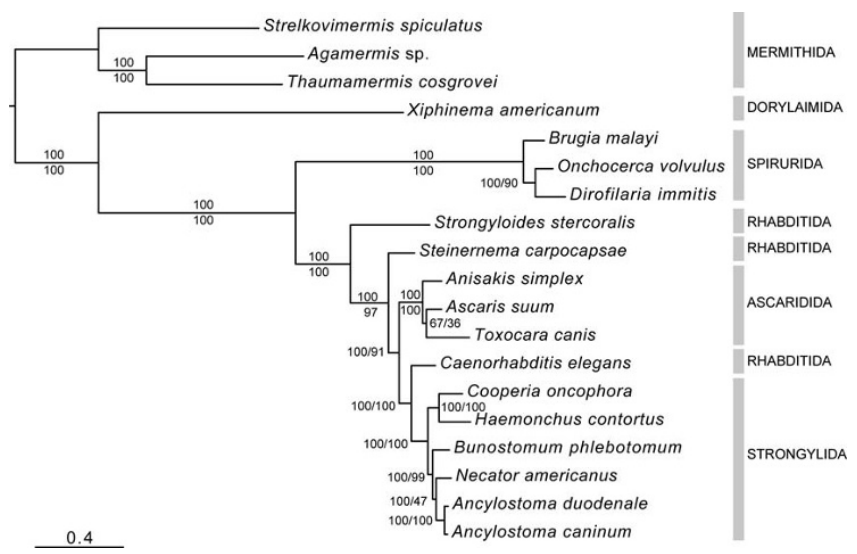

Figure 2

Phylogenetic analysis (using Bayesian inference) of concatenated $\mathrm{mt}$ amino acid sequence data inferred from all protein coding mitochondrial genes $(n=12)$ for 16 secernentean nematodes, including Ancylostoma caninum and Bunostomum phlebotomum (GenBank accession numbers FJ4835 I 8and FJ4835I7, respectively). The concatenated mitochondrial amino acid sequence of three mermithids were employed as outgroups. Bayesian posterior probability values (as a percentage) and maximum likelihood bootstrap support $(n=100)$ are indicated above and below the lines, respectively. The scale indicates an estimate of substitutions per site, using the optimized model setting. 
of the Strongylida, which contrasts markedly the results of a previous study based on nuclear ribosomal gene data (e.g., clade III versus clade V; ref. [53]). The "common heritage" hypothesized herein for the Ascaridida and Strongylida to the exclusion of the Spirurida has been supported by previous studies using $\mathrm{mt}$ gene order data [49] and using concatenated amino acid sequence data inferred from protein-coding $\mathrm{mt}$ genes [38]. These findings stimulate further study of the evolutionary relationships among taxa within this phylum using mt datasets. The highthroughput sequencing potential of 454 technology [54] and the recent validation of this technique for the sequencing of $\mathrm{mt}$ genomes [41] should provide a platform for an in-depth analysis of the phylogeny of the Nematoda.

\section{Conclusion \\ Utility of mt gene markers for population genetic, ecological and epidemiological studies of hookworms}

Although some nuclear genetic regions (e.g., ITS-1 and ITS-2 of nuclear rDNA [22-25] or the cAMP-dependent protein kinase gene [26]) have been shown to be suitable for the specific identification and differentiation of hookworms, the nuclear loci examined to date do not usually display sufficient levels of intraspecific sequence variability for the investigation of the genetic structures of hookworm populations (or the identification of population variants or "strains"). The ability to estimate genetic variability within and among hookworm populations is central to studying their epidemiology and population genetics, and can have important practical implications in relation to control.

Sequence-based analyses (including mutation scanning) of protein-coding mt genes, such as cox 1 and nad1, have been particularly useful or population genetic studies [21,27,29-31,55-59]. For example, Hu et al. [21] employed a single-strand conformation polymorphism (SSCP)-coupled sequencing approach to explore haplotypic variability within a limited number of Ancylostoma caninum specimens from Australia and each of the human hookworms (Ancylostoma duodenale and Necator america$n u s)$. Significant population sub-structuring was recorded within each of these three species, and two genetically distinct subpopulations were detected within Ancylostoma caninum from dogs from Townsville, Australia. Previous morphological and clinical studies had shown that Ancylostoma caninum in Townsville (Australia) is not specific to dogs and can also infect humans (but not complete its life-cycle), causing eosinophilic enteritis [19]. It has been speculated [21] that particular, genetically distinct subpopulations within Ancylostoma caninum can selectively infect the non-canine host. The pattern of haplotypic variability within Ancylostoma caninum might be due to secondary contact between populations or subpopulations, which could have arisen due to host movement from other geographical areas where this hookworm has been recorded and where ecological conditions are distinct; for example, Ancylostoma caninum is endemic in tropical north-east Queensland, Australia [60], but also occurs in the north-west area of Western Australia [61]. It is also possible that feral dogs or dingoes (in different geographical or climatic regions) might harbour one or more genetic variants which might "spill-over" into domestic dogs and/or humans [60]. Future study of the genetic variation among Ancylostoma caninum specimens from domestic and feral dogs, cats and humans as well as between populations from other geographical and climatic regions in Australia and South-East Asia would allow such questions to be addressed. A comparison of the genetic make-up of Ancylostoma caninum from humans affected by eosinophilic enteritis with those from domestic dogs in the Townsville area would be particularly interesting.

In contrast to Ancylostoma caninum, no studies have yet explored the genetics or molecular epidemiology of Bunostomum phlebotomum. Mitochondrial markers might be used to examine sub-structuring in Bunostomum phlebotomum populations in endemic regions of South Africa. In addition, although there has been anecdotal evidence suggesting that Bunostomum phlebotomum may cause cutaneous larval migrans in humans ([20] and unpublished observations [JVW]), the zoonotic potential of this species of hookworm has not yet been tested molecularly. In view of the lack of distinguishing morphological characters allowing the identification of individual larvae, the provision of molecular markers for Bunostomum phlebotomum might allow the extent of the zoonotic potential of this species to be assessed for the first time.

The two mt genomes characterized herein provide a solid foundation for studies of the epidemiology, ecology and population genetics of both Ancylostoma caninum and Bunostomum phlebotomum, which could have important implications for the control of infections by these parasites. Given the lack of morphological characters for specific identification and differentiation of hookworm larvae, there is a clear need for species and population genetic markers for in-depth exploration of the epidemiology of hookworms [59]. Combined with the use of specific markers in the internal transcribed spacers (ITS- 1 and ITS-2) of nuclear rDNA [23-25], investigating the mt haplotypic variability in populations of Ancylostoma caninum and Bunostomum phlebotomum (irrespective of developmental stage) could provide important insights into host affiliations, gene flow and transmission patterns (cf. $[62,63])$ and thus assist in the control of these hookworms. Furthermore, the direct sequencing of the $\mathrm{mt}$ genome of Ancylostoma caninum by 454 technology is the 
second example of the use of this approach for the sequencing of $\mathrm{mt}$ genomes of nematodes [41] and reenforces the exciting potential of emerging technologies for the high-throughput sequencing of relatively small organellar genomes.

\section{Methods \\ Parasites and DNA extraction}

An adult male of Ancylostoma caninum (designated Ac1) was collected (by IB) at necropsy from the duodenum of a dog from Townsville, Australia [23]. An adult male of Bunostomum phlebotomum (Bp1) was collected at autopsy from the same site from a calf monospecifically infected with an isolate of Bunostomum phlebotomum, originally derived from a Jersey cow in Pretoria North suburb, South Africa (by JvW). Nematodes were washed in physiological saline, identified morphologically to species [16], fixed in $50 \%(\mathrm{v} / \mathrm{v})$ ethanol and stored at $-20^{\circ} \mathrm{C}$ until use. Total genomic DNA was isolated from individual worms using sodium dodecyl-sulphate/proteinase $\mathrm{K}$ treatment [64], followed by spin-column purification (Wizard Clean-Up, Promega). The specific identity of each nematode was verified using the sequence of the second internal transcribed spacer (ITS-2) of nuclear ribosomal DNA, which provides species-specific genetic markers for hookworms [25]. The ITS-2 sequence derived from sample Ac1 was identical to that reported previously for Ancylostoma caninum (accession number AJ001591) [25] and that obtained from Bp1 (accession number FJ616999) was 82.3\% identical to the closely related species Bunostomum trigonocephalum (accession number $\underline{\mathrm{AJ001595}}$ ) [25].

\section{Long PCR-coupled mt genome sequencing}

The complete mt genome of each Ancylostoma caninum and Bunostomum phlebotomum was amplified as two overlapping amplicons ( $\sim 10 \mathrm{~kb}$ and $\sim 5 \mathrm{~kb}$, respectively) from $\sim 20-40 \mathrm{ng}$ of the genomic DNA from each specimen by long-PCR (BD Advantage 2, BD Biosciences) using each of the primer pairs $39 \mathrm{~F}-42 \mathrm{R}$ and $5 \mathrm{~F}-40 \mathrm{R}[39,40,42]$, as described by Hu et al. [39], with minor modifications. The cycling conditions (2720 thermal cycler, Applied Biosystems) were: $92^{\circ} \mathrm{C}, 2$ min (initial denaturation); then $92^{\circ} \mathrm{C}, 10 \mathrm{~s}$ (denaturation); $50^{\circ} \mathrm{C}, 30 \mathrm{~s}$ (annealing); $68^{\circ} \mathrm{C}$ (for the $\sim 10 \mathrm{~kb}$ region) or $60^{\circ} \mathrm{C}$ (for the $\sim 5 \mathrm{~kb}$ region), 10 min (extension) for 10 cycles, followed by $92^{\circ} \mathrm{C}, 10 \mathrm{~s}$; $50^{\circ} \mathrm{C}, 30 \mathrm{~s} ; 68^{\circ} \mathrm{C}$ or $60^{\circ} \mathrm{C}, 10 \mathrm{~min}$ for 20 cycles, with an elongation period of $10 \mathrm{~s}$ for each cycle, and a final extension at $68^{\circ} \mathrm{C}$ or $60^{\circ} \mathrm{C}$ for $7 \mathrm{~min}$. Following the PCR, individual amplicons were resolved in ethidium bromidestained agarose $(1 \%)$ gels and shown to represent single bands. Amplicon size was estimated based on comparison with a $1 \mathrm{~kb}$ DNA size ladder (Promega). Amplicons of $\sim 10$ $\mathrm{kb}$ or $\sim 5 \mathrm{~kb}$ were purified over a mini-column (Wizard PCR Preps, Promega). Subsequently, the amount of DNA in each purified amplicon was estimated spectrophoto- metrically (ND-1000 UV-VIS spectrophotometer, v.3.2.1, NanoDrop Technologies). The purified amplicons were then subjected to sequencing.

The mt genome of Ancylostoma caninum (designated AcMG-454; GenBank accession no. FJ483518) was sequenced ( 454 technology by AJ/RBG) using a Genome Sequencer 20 (Roche), according to an established protocol [54]. The complete mt genome of Bunostomum phlebotomum (designated BpMG-PW; GenBank accession no. FJ483517) was sequenced (AW/DTL) by primer walking, as described previously [44]. The AcMG-454 sequence was assembled automatically, whereas that of BpMG-PW was assembled manually using Sequencher v.4.8 (Gene Codes Corporation). Both $\mathrm{mt}$ genome sequences were annotated and subjected to analysis using standard approaches $[41,44]$, and their structures were compared with each other and with those of the two human hookworms, Ancylostoma duodenale (GenBank accession number AJ417718; ref. [42] and Necator americanus (AJ417719; ref. [42], Haemonchus contortus (EU346694; ref. [41]) (Strongylida); Anisakis simplex (AY994157; ref. [43], Ascaris suum (X53453; ref. [45]), and Toxocara canis (EU730761; ref. [44]) (Ascaridida); Brugia malayi (AF538716; ref. [46]), Dirofilaria immitis (AJ537512; ref. [47]) and Onchocerca volvulus ( $\underline{\mathrm{AF015193}}$; ref. [48]) (Spirurida).

\section{Phylogenetic analysis}

The analysis of amino acid sequence data was conducted via Bayesian inference (BI) using the software package MrBayes v.3.1.2 http://mrbayes.csit.fsu.edu/index.php and maximum likelihood (ML) using GARLI ([65]; http:/ /www.bio.utexas.edu/faculty/antisense/garli/Garli.html), each running on a four dual-core Opteron-based Unix cluster. For individual species, the amino acid sequences inferred from all protein coding $\mathrm{mt}$ genes were concatenated. A selection of published mermithid mt genomes were used as outgroups (Strelkovimermis spiculatus, accession NC 008047; Agamermis sp., NC 008231; Thaumermis cosgrovei, NC 008046) and included a range of ingroup taxa (Xiphinema americanum, NC 005928; Brugia malayi, NC004298; Onchocerca volvulus, NC 001861; Dirofilaria immitis, NC 005305; Strongyloides stercoralis, NC_005143; Caenorhabditis elegans, NC_001328; Steinernema carpocapsae, NC_005941; Necator americanus, NC 003416; Ancylostoma duodenale, NC 003415; Cooperia oncophora, NC 004806; Haemonchus contortus, NC 010383; Anisakis simplex, NC 007934; Ascaris suum, NC_003127; Toxocara canis, NC_010690). Amino acid sequences were aligned using MUSCLE [66]. Ambiguous sites were excluded using G-Blocks $([67,68]$; see Additional File 1 for alignment).

For BI of amino acid data, tree construction and posterior probabilities (pp) were calculated via 2000000 genera- 
tions (ngen $=2000000)$ using the Metropolis-coupled Monte Carlo Markov Chain (MCMCMC) method and four simultaneous tree-building chains (nchains $=4$ ), with every $10^{\text {th }}$ tree being saved (samplefreq $=10$ ). A suitable burnin (burnin $=1000$ ) was chosen using 'Trace' in the program Tracer v1.4 http://beast.bio.ed.ac.uk/. Evolutionary distance was estimated using the most appropriate amino acid model and calculated employing the MrBayes program $($ aamodelpr $=$ mixed $)$, allowing for a gammashaped variation in mutation rates with a proportion of invariable sites (rates = invgamma). Upon completion of the analysis, a $50 \%$ majority rule $=$ consensus tree was constructed in TreeviewX v.0.5.0 http://darwin.zool ogy.gla.ac.uk/ rpage/treeviewx/. For the ML analysis using GARLI, tree construction was estimated with the model GTR+I+g using the mtRev amino acid substitution matrix, for two replicate runs, and termination criteria with setting genthresholdfortopoterm $=20000$ (no new significantly better scoring topology found in $>20000$ generations). Nodal support in the ML analysis was estimated by bootstrap re-sampling $(n=100)$ using GARLI and the same model settings.

\section{Authors' contributions}

ARJ and RBG conceived the study. ARJ and AW contributed equally to molecular work, assisted by MH. DTJL provided technical advice and conducted phylogenetic analyses. IB and JvW provided morphologically-identified parasite material. ARJ and RBG drafted the manuscript, with active inputs from all other authors. All authors approved the final manuscript.

\section{Additional material}

\section{Additional file 1}

Amino acid alignment of all nematode taxa used for phylogenetic analysis. Alignment output from Gblocks. The Gblocks server http:// molevol.cmima.csic.es/castresana/Gblocks server.html was used to align the concatenated amino acids using the most conserved settings. Blocks of "XXXX" represent markers between genes and were not included in the analyses; parameters are listed at the end of the alignment. Gblocks selected 2837 positions (marked ${ }^{*}$ ) to be included. Gene partitions are in the following order: atp6, cox1, cox2, cox3, cytb, nad1, nad2, nad3, nad4, nad4L, nad5, nad6. The concatenated $m t$ genomic sequences used in the alignment represent species of Mermithida (Agamermis sp., Thaumamermis cosgrovei and Strelkovimermis spiculatus), Ascardida (Anisakis simplex, Ascaris suum and Toxocara canis), Dorylaimida (Xiphenema americanum), Rhabditida (Caenorhabditis elegans, Steinernema carpocapsae and Strongyloides stercoralis), Spirurida (Brugia malayi, D. immitis and O. volvulus) and Strongylida (Ancylostoma caninum, Ancylostoma duodenale, Bunostomum phlebotomum, Cooperia oncophora, Haemonchus contortus and Necator americanus). The species used as outgroups are denoted in bold text.

Click here for file

[http://www.biomedcentral.com/content/supplementary/1471-

2164-10-79-S1.doc]

\section{Acknowledgements}

Support from the Australian Research Council (LX0775848 and LX08822 I5) (ARJ, DTJL and RBG), the Australian Academy of Science and the Australian-American Fulbright Commission (RBG) is gratefully acknowledged.

\section{References}

I. Miller TA: Vaccination against the canine hookworm diseases. Adv Parasitol I97I, 9:153-183.

2. Yu SH, Shen WX: Hookworm infection and disease in China. In Hookworm Disease: Current Status and New Directions Edited by: Schad G, Warren KS. London: Taylor and Francis; 1990:44-54.

3. Nàquira C: Hookworm infection in Latin America and the Caribbean. In Hookworm Disease: Current Status and New Directions Edited by: Schad G, Warren KS. London: Taylor and Francis; 1990:55-68.

4. Kilama WL: Hookworm Infection and Disease in Africa and the Middle East. In Hookworm Disease: Current Status and New Directions Edited by: Schad G, Warren KS. London: Taylor and Francis; 1990:17-32.

5. Carroll SM, Walker JC: Hookworm infection in Southeast Asia, Oceania and Australia. In Hookworm Disease: Current Status and New Directions Edited by: Schad G, Warren KS. London: Taylor and Francis; 1990:33-43.

6. Yu SH, Jiang ZX, Xu LQ: Infantile hookworm disease in China. A review. Acta Trop 1995, 59(4):265-270.

7. Beveridge I: Australian hookworms (Ancylostomatoidea): a review of the species present, their distributions and biogeographical origins. Parassitologia 2002, 44(I-2):83-88.

8. Heukelbach J, Feldmeier H: Epidemiological and clinical characteristics of hookworm-related cutaneous larva migrans. Lancet Infect Dis 2008, 8(5):302-309.

9. de Silva NR, Brooker S, Hotez PJ, Montresor A, Engels D, Savioli L: Soil-transmitted helminth infections: Updating the global picture. Trends Parasitol 2003, 19:547-55I.

10. Hotez PJ, Bethony J, Bottazzi ME, Brooker S, Buss P: Hookworm: "The Great Infection of Mankind". PLoS Med 2005, 2(3):e67.

II. WHO: Deworming for Health and Development. Report of the Third Global Meeting of the Partners for Parasite Control 2005 [http:// whqlibdoc.who.int/hq/2005/who cds cpe pvc 2005. I4.pdf]. Geneva: World Health Organization

12. Guest CM, Stephen JM, Price CJ: Prevalence of Campylobacter and four endoparasites in dog populations associated with Hearing Dogs. J Small Anim Pract 2007, 48(I I):632-637.

13. Smith GC, Gangadharan B, Taylor Z, Laurenson MK, Bradshaw H, Hide G, Hughes JM, Dinkel A, Romig T, Craig PS: Prevalence of zoonotic important parasites in the red fox (Vulpes vulpes) in Great Britain. Vet Parasitol 2003, I I 8(I-2):133-142.

14. Yazwinski TA, Gibbs HC: Survey of helminth infections in Maine dairy cattle. Am J Vet Res 1975, 36(I I):1677-I682.

15. Anderson TC, Foster GW, Forrester DJ: Hookworms of feral cats in Florida. Vet Parasitol 2003, I I 5(I): 19-24.

16. Skrjabin KI, Shikhobalova NP, Schulz RS, Popova TI, Boev SN, Delyamure SL: Strongylata. Keys to Parasitic Nematodes. In [English Translation of Opredelitel' Paraziticheskikh Nematod. Izdatel'stvo Akademii Nauk SSSR, Moscow] Volume 3. Edited by: Skrjabin KI. Amerind Publishing Co. Pvt. Ltd; 1992.

17. Biocca E: Rediscrizione di Ancylostoma tubaeforme (Zedler, 1800) parassita del gatto, considerato erroneamente sinonimo di Ancylostoma caninum (Ercolani, 1859) parassita del carne. Riv Parassitol 1954, 15:267-278.

18. Burrows RB: Comparative morphology of Ancylostoma tubaeforme (Zeder, 1800) and Ancylostoma caninum (Ercolani, 1859). J Parasitol 1962, 48:715-718.

19. Prociv P, Croese J: Human enteric infection with Ancylostoma caninum: hookworms reappraised in the light of a "new" zoonosis. Acta Trop 1996, 62(I):23-44.

20. Mayhew RL: Creeping eruption caused by the larvae of the cattle hookworm Bunostomum phlebotomum. Proc Soc Exp Biol Med 1947, 66:12-14.

21. Hu M, Chilton NB, Zhu X, Gasser RB: Single-strand conformation polymorphism-based analysis of mitochondrial cytochrome $c$ oxidase subunit I reveals significant substructuring in hookworm populations. Electrophoresis 2002, 23(I):27-34. 
22. Rømstad A, Gasser RB, Nansen P, Polderman AM, Chilton NB: Necator americanus (Nematoda: Ancylostomatidae) from Africa and Malaysia have different ITS-2 rDNA sequences. Int J Parasitol I 998, 28(4):6| |-6|5.

23. Gasser RB, Stewart LE, Speare R: Genetic markers in ribosomal DNA for hookworm identification. Acta Trop 1996, 62(I): I5-2I.

24. Gasser RB, Monti JR, Bao-Zhen Q, Polderman AM, Nansen P, Chilton NB: A mutation scanning approach for the identification of hookworm species and analysis of population variation. Mol Biochem Parasitol 1998, 92(2):303-312.

25. Chilton NB, Gasser RB: Sequence differences in the internal transcribed spacers of DNA among four species of hookworm (Ancylostomatoidea: Ancylostoma). Int J Parasitol 1999. 29(I 2): 197|-1977.

26. Hawdon JM: Differentiation between the human hookworms Ancylostoma duodenale and Necator americanus using PCRRFLP. J Parasitol 1996, 82(4):642-647.

27. Hawdon JM, Li T, Zhan B, Blouin MS: Genetic structure of populations of the human hookworm, Necator americanus, in China. Mol Ecol 200I, I0(6): |433-|437.

28. Hu M, Chilton NB, Abs EL-Osta YG, Gasser RB: Comparative analysis of mitochondrial genome data for Necator americanus from two endemic regions reveals substantial genetic variation. Int J Parasitol 2003, 33(9):955-963.

29. Li TH, Guo XR, Xue J, Hu L, Qiang HQ, Xue HC, Bin Z, Hawdon JM, Xiao SH: Comparison of mitochondrial cytochrome oxidase I DNA sequences from Necator americanus hookworms maintained for 100 generations in golden hamsters (Mesocricetus auratus) and hookworms from natural human infections. Acta Trop 2004, 92(I):7I-75.

30. Moser JM, Carbone I, Arasu P, Gibson G: Impact of population structure on genetic diversity of a potential vaccine target in the canine hookworm (Ancylostoma caninum). J Parasitol 2007 93(4):796-805.

31. Miranda RR, Tennessen JA, Blouin MS, Rabelo EM: Mitochondrial DNA variation of the dog hookworm Ancylostoma caninum in Brazilian populations. Vet Parasitol 2008, I 5 I (I):6 I-67.

32. Brown WM: The mitochondrial genome of animals. In Molecular Evolutionary Genetics Edited by: Maclntyre RJ. New York: Plenum Press; 1985:95-130.

33. Avise JC, Arnold J, Ball RM, Berminham E, Lamb T, Neigel JE, Carol AR, Saunder NC: Intraspecific phylogeography: the mitochondrial DNA bridge between population genetics and systematics. Ann Rev Ecol Syst 1987, I 8:489-522.

34. Avise JC: Molecular markers, natural history and evolution. New York and London: Chapman and Hall; 1994.

35. Bowles J, Blair D, McManus DP: Genetic variants within the genus Echinococcus identified by mitochondrial DNA sequencing. Mol Biochem Parasitol 1992, 54(2): I65-I73.

36. Bøgh HO, Zhu XQ, Qian BZ, Gasser RB: Scanning for nucleotide variations in mitochondrial DNA fragments of Schistosome japonicum by single-strand conformation polymorphism. Parasitology 1999, I I 8(Pt I):73-82.

37. Hu M, Gasser RB: Mitochondrial genomes of parasitic nematodes - progress and perspectives. Trends Parasitol 2006 22(2):78-84

38. Hu M, Chilton NB, Gasser RB: The mitochondrial genomics of parasitic nematodes of socio-economic importance: recent progress, and implications for population genetics and systematics. Adv Parasitol 2004, 56:133-2 I 2.

39. Hu M, Chilton NB, Gasser RB: Long PCR-based amplification of the entire mitochondrial genome from single parasitic nematodes. Mol Cell Probes 2002, I 6(4):26I-267.

40. Hu M, Jex AR, Campbell BE, Gasser RB: Long PCR amplification of the entire mitochondrial genome from individual helminths for direct sequencing. Nat Protoc 2007, 2:2339-2344.

4I. Jex AR, Hu M, Littlewood DT, Waeschenbach A, Gasser RB: Using 454 technology for long-PCR based sequencing of the complete mitochondrial genome from single Haemonchus contortus (Nematoda). BMC Genomics 2008, 9: I I

42. Hu M, Chilton NB, Gasser RB: The mitochondrial genomes of the human hookworms, Ancylostoma duodenale and Necator americanus (Nematoda: Secernentea). Int J Parasitol 2002, 32(2): | $45-158$.
43. Kim KH, Eom KS, Park JK: The complete mitochondrial genome of Anisakis simplex (Ascaridida: Nematoda) and phylogenetic implications. Int J Parasitol 2006, 36:319-328.

44. Jex AR, Waeschenbach A, Littlewood DTJ, Hu M, Gasser RB: The mitochondrial genome of Toxocara canis - a rich source of genetic markers for systematic and epidemiological studies. PLoS Negl Trop Dis 2008, 2(8):e273.

45. Okimoto R, Macfarlane JL, Clary DO, Wolstenholme DR: The mitochondrial genomes of two nematodes, Caenorhabditis elegans and Ascaris suum. Genetics 1992, 130(3):47I-498.

46. Ghedin E, Wang S, Spiro D, Caler E, Zhao Q, Crabtree J, Allen JE, Delcher AL, Guiliano DB, Miranda-Saavedra D, et al: Draft genome of the filarial nematode parasite Brugia malayi. Science 2007, 3 | 7(5845): | 756- 1760 .

47. Hu M, Gasser RB, Abs EL-Osta YG, Chilton NB: Structure and organization of the mitochondrial genome of the canine heartworm, Dirofilaria immitis. Parasitology 2003, I 27(Pt I):37-5I.

48. Keddie EM, Higazi T, Unnasch TR: The mitochondrial genome of Onchocerca volvulus: sequence, structure and phylogenetic analysis. Mol Biochem Parasitol I 998, 95( I): I I I-I 27

49. Hu M, Chilton NB, Gasser RB: The mitochondrial genome of Strongyloides stercoralis (Nematoda) - idiosyncratic gene order and evolutionary implications. Int J Parasitol 2003, 33( I 2): | 393-1408.

50. Okimoto R, Wolstenholme DR: A set of tRNAs that lack either the $T$ psi $C$ arm or the dihydrouridine arm: towards a minimal tRNA adaptor. EMBO J I990, 9(I 0):3405-34II.

5I. Wolstenholme DR, Macfarlane JL, Okimoto R, Clary DO, Wahleithner JA: Bizarre tRNAs inferred from DNA sequences of mitochondrial genomes of nematode worms. Proc Natl Acad Sci USA 1987, 84(5): | 324-| 328.

52. Blouin MS: Mitochondrial DNA diversity in nematodes. Helminthol I998, 72(4):285-289.

53. Blaxter ML, De Ley P, Garey JR, Liu LX, Scheldeman P, Vierstraete A, Vanfleteren JR, Mackey LY, Dorris M, Frisse LM, et al.: A molecular evolutionary framework for the phylum Nematoda. Nature 1998, 392:7|-75.

54. Margulies M, Egholm M, Altman WE, Attiya S, Bader JS, Bemben LA Berka J, Braverman MS, Chen YJ, Chen Z, et al:: Genome sequencing in microfabricated high-density picolitre reactors. Nature 2005, 437(7057):376-380.

55. Anderson T], Romero-Abal ME, Jaenike J: Mitochondrial DNA and Ascaris microepidemiology: the composition of parasite populations from individual hosts, families and villages. Parasitology 1995, I I 0(Pt 2):221-229.

56. Blouin MS, Yowell CA, Courtney CH, Dame JB: Haemonchus placei and Haemonchus contortus are distinct species based on mtDNA evidence. Int J Parasitol 1997, 27( I I): I 383- I 387

57. Blouin MS: Molecular prospecting for cryptic species of nematodes: mitochondrial DNA versus internal transcribed spacer. Int J Parasitol 2002, 32(5):527-53I.

58. Hu M, Rabelo EM, Schindler AR, Roberts H, Gasser RB: Extensive and complex sequence diversity in mitochondrial cytochrome c oxidase subunit I within Necator americanus from Colombia revealed by SSCP-coupled sequencing. Mol Cell Probes 2008, 22(4):234-237.

59. Gasser RB, Cantacessi C, Loukas A: DNA technological progress toward advanced diagnostic tools to support human hookworm control. Biotechnol Adv 2008, 26(I):35-45.

60. Prociv P, Collyer R, Lim K, Tang R: Brisbane dogs as a reservoir of zoonotic hookworms. Med J Aust 1994, I6 I(2): I72-I73.

6I. Thompson RC, Meloni BP, Hopkins RM, Deplazes P, Reynoldson JA: Observations on the endo- and ectoparasites affecting dogs and cats in aboriginal communities in the north-west of Western Australia. Aust Vet J 1993, 70(7):268-270

62. Hu M, Höglund J, Chilton NB, Zhu X, Gasser RB: Mutation scanning analysis of mitochondrial cytochrome $c$ oxidase subunit I reveals limited gene flow among bovine lungworm subpopulations in Sweden. Electrophoresis 2002, 23( I 9):3357-3363.

63. Peng W, Yuan K, Hu M, Gasser RB: Recent insights into the epidemiology and genetics of Ascaris in China using molecular tools. Parasitology 2007, I34(Pt 3):325-330.

64. Gasser RB, Chilton NB, Hoste H, Beveridge I: Rapid sequencing of rDNA from single worms and eggs of parasitic helminths. Nucleic Acids Res 1993, 2 I ( I 0):2525-2526. 
65. Zwickl DJ: Genetic algorithm approaches for the phylogenetic analysis of large biological sequence datasets under the maximum likelihood criterion. In PhD Dissertation Austin: University of Texas; 2006.

66. Edgar RC: MUSCLE: multiple sequence alignment with high accuracy and high throughput. Nucleic Acids Res 2004, 32:1792-1797.

67. Castresana J: Selection of conserved blocks from multiple alignments for their use in phylogenetic analysis. Mol Biol Evol 2000, 17:540-552.

68. Talavera G, Castresana J: Improvement of phylogenies after removing divergent and ambiguously aligned blocks from protein sequence alignments. Syst Biol 2007, 56:564-577.

Publish with Bio Med Central and every scientist can read your work free of charge

"BioMed Central will be the most significant development for disseminating the results of biomedical research in our lifetime. "

Sir Paul Nurse, Cancer Research UK

Your research papers will be:

- available free of charge to the entire biomedical community

- peer reviewed and published immediately upon acceptance

- cited in PubMed and archived on PubMed Central

- yours - you keep the copyright

Submit your manuscript here:

http://www.biomedcentral.com/info/publishing_adv.asp
BioMedcentral 